\title{
Atomic Absorption Spectrometry as an Alternative to Determine the Presence of Gold Nanoparticles on or in Silica Matrix
}

\author{
Cristian J. Giertyas, ${ }^{a}$ Victor E. S. Silva, ${ }^{a}$ Maria J. de Oliveira, ${ }^{b}$ Emerson S. Freire, ${ }^{b}$ \\ Josué C. C. Santos, ${ }^{\circledR b}$ Rusiene M. de Almeida, ${ }^{\circledR a}$ Mario R. Meneghetti ${ }^{\circledR a}$ and \\ Janaína H. Bortoluzzi ${ }^{\odot *, a}$ \\ ${ }^{a}$ Grupo de Catálise e Reatividade Química, Instituto de Química e Biotecnologia (GCaR), \\ Universidade Federal de Alagoas, Avenida Lourival de Melo Mota s/n, \\ Campus A.C. Simões, 57072-900 Maceió-AL, Brazil \\ ${ }^{b}$ Laboratório de Instrumentação e Desenvolvimento em Química Analítica (LINQA), \\ Universidade Federal de Alagoas, Avenida Lourival de Melo Mota s/n, \\ Campus A.C. Simões, 57072-900 Maceió-AL, Brazil
}

\begin{abstract}
Two different gold-silica-based nanomaterials were prepared: (i) silica-supported gold nanoparticles $\left(\mathrm{AuNP} / \mathrm{SiO}_{2}\right)$; and (ii) gold-silica core-shell nanoparticles $\left(\mathrm{AuNP} @ \mathrm{SiO}_{2}\right)$. Three strategies for sample treatment (S), consisting in acid treatments, were employed: (S1) $\mathrm{HNO}_{3}$; (S2) $\mathrm{HNO}_{3}+\mathrm{HCl}$; and $(\mathrm{S} 3) \mathrm{HF}+\mathrm{HNO}_{3}+\mathrm{HCl}$, applying microwave oven digestion for $\mathrm{S} 2$ and $\mathrm{S} 3$. From three calibration curves, slope, intercept, and linear correlation coefficient were obtained. The accuracy of the methods was evaluated by comparing the gold contents in a sample determined by flame atomic absorption spectrometry (FAAS) and by inductively coupled plasma atomic emission spectrometry (ICP-OES). Finally, the amount of gold for all samples was determined by FAAS. UV-Vis spectroscopy and transmission electron microscopy (TEM) were used to compare the material before and after sample treatment. By comparison, the application of S2 and S3 allowed the presence of gold on or in the silica matrix to be determined and the amount quantified.
\end{abstract}

Keywords: core-shell nanoparticles, supported metal nanoparticles, characterization of nanoparticles, gold, silica, flame atomic absorption spectrometry, sample preparation

\section{Introduction}

Metallic nanoparticles, along with their salts and oxide derivatives, have several applications in important areas, including catalysis and biomedicine. ${ }^{1-3}$ In general, these metal-based nanoparticles are not employed in their isolated pure form but are associated with other organic or inorganic components to provide them with stability or a particular property or potential use. However, materials containing different components are more complex in terms of determining and quantifying their components. ${ }^{4}$

Gold nanoparticles (AuNPs) have a wide variety of applications, mostly due to the unique physicochemical properties of metallic gold when it is in these dimensions. ${ }^{3}$ It should be noted that, for specific applications, AuNPs are normally supported on or surrounded by an oxide,

*e-mail: janaina.bortoluzzi@iqb.ufal.br

Editors handled this article: Jaísa Fernandes Soares and Pedro H. C. Camargo (Associate) for example, silica..$^{5-8}$ Nanostructured silica presents interesting properties for nanotechnological applications. Silica offers good thermal and chemical stability and biocompatibility, but its surface chemistry is versatile, allowing the functionalization and modulation of its hydrophilicity. Furthermore, in general, nanostructured silica can be easily synthesized in large scale and at low cost. The combination of these attractive characteristics have led to a large variety of silica nanoformulations being proposed and investigated. ${ }^{9}$

All of these nanostructures can be characterized using techniques to determine structural aspects, such as transmission electron microscopy (TEM), scanning tunneling microscopy (STM), scanning electron microscopy (SEM), atomic force microscopy (AFM) and X-ray diffraction (XRD). To determine the chemical composition, energy dispersive X-ray analysis (EDX), $\mathrm{X}$-ray photoelectron spectroscopy (XPS), near-edge X-ray absorption fine structure (NE XAFS) and extended X-ray 
absorption fine structure (EXAFS) can be employed. ${ }^{10,11}$ However, TEM is the technique most commonly used for both structural resolution and chemical mapping. ${ }^{11-15}$ This technique allows the silica-supported gold $\left(\mathrm{AuNP} / \mathrm{SiO}_{2}\right)$ and core-shell (AuNP@ $\mathrm{SiO}_{2}$ ) nanostructured systems to be distinguished. On the other hand, for elemental quantification, spectrometric techniques like atomic absorption spectrometry (AAS) (electro-thermal or with flame atomization) and inductively coupled plasma atomic emission spectrometry (ICP-OES), in some cases associated with mass spectrometry, are generally applied. However, when AAS and ICP-OES are used for elemental quantification the sample preparation strategy for a silicasupported metal nanoparticle system it is not necessarily the same as that for an analogous core-shell-like system (e.g., for $\mathrm{AuNP} / \mathrm{SiO}_{2}$ and $\mathrm{AuNP} @ \mathrm{SiO}_{2}$ ).

In view of this, we evaluated the wet sample preparation processes for AuNP/SiO ${ }_{2}$ and AuNP@ $\mathrm{SiO}_{2}$ systems, adopting different sample preparation strategies based on mixtures of oxidizing $\left(\mathrm{HNO}_{3}\right)$ and complexing $(\mathrm{HCl}$ and $\mathrm{HF}$ ) acids, associated with microwave-assisted digestion. Finally, the quantification of the gold content in the different nanostructured systems was performed by flame atomic absorption spectrometry (FAAS).

\section{Experimental}

\section{Synthesis of gold-silica-based nanomaterials}

The nanoparticles were prepared employing the experimental protocol described by Huh et al. ${ }^{16}$ and Trewyn et al. ${ }^{17}$ for $\mathrm{AuNP} / \mathrm{SiO}_{2}$, and Arnal et al. ${ }^{18}$ and Fang et al. ${ }^{19}$ for AuNP@ $\mathrm{SiO}_{2}$, with some adaptations.

\section{Synthesis of silica-supported gold nanoparticles (AuNP/SiO $)$}

Briefly, in a $1 \mathrm{~L}$ Teflon beaker, deionized water $(600 \mathrm{~mL}$, obtained from a MilliQ-Plus filtration system, Millipore ${ }^{\circledR}$, Merck, Darmstadt, Germany), an aqueous solution of $\mathrm{NaOH}\left(6.0 \mathrm{~mL}\right.$ of $2.0 \mathrm{~mol} \mathrm{~L}^{-1}$; Dinâmica Química Contemporânea LTDA, São Paulo, Brazil) and hexadecyl trimethylammonium bromide (CTAB) $(0.50 \mathrm{~g}$, Acros Organics, Geel, Belgium) were mixed and heated to $50^{\circ} \mathrm{C}$. After $15 \mathrm{~min}$, an aqueous solution of $\mathrm{HAuCl}_{4} \cdot 3 \mathrm{H}_{2} \mathrm{O}(12 \mathrm{~mL}$; $1 \% \mathrm{~m} / \mathrm{v}$; Sigma-Aldrich, Missouri, USA) was added and, after homogenizing the solution, tetraethylorthosilicate (TEOS) (3.3 mL; 95\%, Sigma-Aldrich, Missouri, USA) was added. After $2 \mathrm{~h}$ at $50{ }^{\circ} \mathrm{C}$, the solid was recovered by filtration and washed with deionized water until all excess base had been removed. The solid obtained was dried in an oven at $80{ }^{\circ} \mathrm{C}$ for $24 \mathrm{~h}$. Lastly, the solid was calcined at $550^{\circ} \mathrm{C}$ for $4 \mathrm{~h}$ with a heating rate of $5^{\circ} \mathrm{C}$ per min under ambient atmosphere. At the end of the process a red solid material $(0.3 \mathrm{~g})$ was obtained.

Synthesis of gold-silica core-shell nanoparticles (AuNP@ $\mathrm{SiO}_{2}$ )

Briefly, spherical AuNPs were prepared in a $500-\mathrm{mL}$ reaction flask with the addition of deionized water $(280 \mathrm{~mL})$ and an aqueous solution of $\mathrm{HAuCl}_{4} \cdot 3 \mathrm{H}_{2} \mathrm{O}(7.5 \mathrm{~mL} ; 1 \% \mathrm{~m} / \mathrm{v}$; Sigma-Aldrich, Missouri, USA). The solution was heated under reflux, when an aqueous solution of sodium citrate (4.2 mL; 3\% m/v; Sigma-Aldrich, Missouri, USA) was added. The mixture changed color from yellow to dark red and remained under reflux for a further $30 \mathrm{~min}$. After reaching room temperature, an aqueous solution of polyvinylpyrrolidone (PVP) $\left(1.0 \mathrm{~mL} ; 12.8 \mathrm{~g} \mathrm{~L}^{-1}\right.$; SigmaAldrich, Missouri, USA) was added and the mixture was kept under stirring for $24 \mathrm{~h}$. PVP-stabilized AuNPs were centrifuged at $13500 \mathrm{rpm}$ for $20 \mathrm{~min}$ and dispersed in deionized water $(55 \mathrm{~mL})$. In the second stage, the colloidal solution of AuNPs was added in a Teflon beaker flask $(500 \mathrm{~mL})$ with isopropanol $(400 \mathrm{~mL}$; Tedia, Rio de Janeiro, Brazil) and an aqueous solution of ammonium hydroxide $(11.0 \mathrm{~mL} ; 28 \% \mathrm{~m} / \mathrm{m}$; Dinâmica Química Contemporânea LTDA, São Paulo, Brazil). After 5 min of mixing, tetraethylorthosilicate (TEOS) $(3.3 \mathrm{~mL} ; 95 \%$, Sigma-Aldrich, Missouri, USA) was added dropwise under vigorous stirring, with $1.0 \mathrm{~mL}$ being dropped every $5 \mathrm{~min}$ into the solution. The solution was covered with aluminum foil and left for $12 \mathrm{~h}$ under stirring. The solid formed was collected by centrifugation (13500 rpm per $20 \mathrm{~min}$ ) and then washed with a solution of ethanol/deionized water $(1: 1 ; 3 \times 20 \mathrm{~mL})$ and dried in an oven at $80{ }^{\circ} \mathrm{C}$ for 24 h. Lastly, the solid was calcined at $550^{\circ} \mathrm{C}$ for $4 \mathrm{~h}$ with a heating rate of $5{ }^{\circ} \mathrm{C}$ per min under ambient atmosphere. At the end of the process a red solid material $(1.1 \mathrm{~g})$ was obtained.

\section{Determination of the gold content}

The gold content for both nanostructured materials was determined by flame atomization atomic absorption spectrometry (Shimadzu, AA-7000, Kyoto, Japan), using $\lambda=242.8 \mathrm{~nm}$ and a hollow gold cathode lamp. In all three wet sample preparation strategies, $50 \mathrm{mg}$ of sample was used. For $\mathrm{S} 1,10 \mathrm{~mL}$ of $\mathrm{HNO}_{3}$ at $2.0 \mathrm{~mol} \mathrm{~L}^{-1}$ (Merck, Darmstadt, Germany) were added, and the extraction procedure was applied with $30 \mathrm{~min}$ of stirring at $600 \mathrm{rpm}$. The samples were then filtered through cellulose acetate membranes $(0.45 \mu \mathrm{m})$. For $\mathrm{S} 2$ the mineralization procedure was performed in an Ethos One high-pressure closed 
microwave (MW) digestion system (Milestone, Sorilose, Italy), equipped with ten (SK-10) rotors, using mixtures of concentrated acids: $\mathrm{S} 2,2.0 \mathrm{~mL} 65 \%(\mathrm{~m} / \mathrm{m}) \mathrm{HNO}_{3}$ with $6.0 \mathrm{~mL} 37 \%(\mathrm{~m} / \mathrm{m}) \mathrm{HCl}(1: 3$, aqua regia, Merck, Darmstadt, Germany) and $1.0 \mathrm{~mL}$ of ultrapure water were added (conductivity $<0.1 \mu \mathrm{S} \mathrm{cm} \mathrm{cm}^{-1}$ ). The procedure for $\mathrm{S} 3$ was the same as that for $\mathrm{S} 2$ but with the addition of $1.0 \mathrm{~mL} \mathrm{HF}$ $48 \%(\mathrm{~m} / \mathrm{m})$ (Sigma-Aldrich, Missouri, USA) in the place of water. After adding the reagents, the reactors were closed and the heating program (Table 1) was started, according to the conditions recommended by Niemelä et al..$^{20}$

Table 1. Digestion program of nanoparticle samples by microwave radiation

\begin{tabular}{lccc}
\hline Stage & time $/ \mathrm{min}$ & Power $/ \mathrm{W}$ & Temperature $/{ }^{\circ} \mathrm{C}$ \\
\hline I & $15^{\mathrm{a}}$ & 1000 & from RT to 200 \\
II & $10^{\mathrm{b}}$ & 1000 & 200 \\
\hline
\end{tabular}

${ }^{a}$ Heating ramp time; ${ }^{b}$ landing time. RT: room temperature.

Pressurized and closed system digestions were performed in triplicate $(n=3)$ and, in each procedure, the three reactors contained blank analytical solutions. After the above-mentioned steps (Table 1), the reactors were kept under ventilation for $20 \mathrm{~min}$ and then opened and the digested material was cooled to room temperature. The solutions resulting from S2 were filtered $(0.45 \mu \mathrm{m})$ to separate undissolved silica $\left(\mathrm{SiO}_{2}\right)$ and diluted to $25 \mathrm{~mL}$ with ultrapure water while those resulting from S3 were additionally treated with $0.50 \mathrm{~g}$ of $\mathrm{H}_{3} \mathrm{BO}_{3}$ (SigmaAldrich, Missouri, USA) to eliminate the excess HF present in the reaction medium. The residual acidity of the digests was determined by acid-base titration, using a standardized sodium hydroxide solution $\left(0.0900 \mathrm{~mol} \mathrm{~L}^{-1}\right)$ and $1.0 \%(\mathrm{~m} / \mathrm{v})$ phenolphthalein as a visual indicator. Calibration curves (1.0 to $25 \mathrm{mg} \mathrm{L}^{-1} \mathrm{Au}$ content, $\mathrm{n}=7$ ) for the gold determination were constructed from the gold precursor salt $\left(\mathrm{HAuCl}_{4} \cdot 3 \mathrm{H}_{2} \mathrm{O}\right.$, Sigma-Aldrich, Missouri, USA) and used for the nanoparticle synthesis. For each strategy, a calibration curve was prepared considering the composition and final concentration of the acid mixture.

The efficiency of the proposed methodology to determine the gold content of the gold-silica samples was confirmed by comparing the results obtained for a $\mathrm{AuNP} / \mathrm{SiO}_{2}$ sample analyzed by ICP-OES carried out at the Analytical Center of the Chemistry Institute of the University of São Paulo. In this procedure a Spectro ICP-OES spectrometer, model Arcos (Kleve, Germany), was used with the following parameters: frequency, $27.12 \mathrm{MHz}$; power, $1400 \mathrm{~W}$; argon flow rates for plasma, $12 \mathrm{~L} \mathrm{~min}^{-1}$; auxiliary, $1 \mathrm{~L} \mathrm{~min}^{-1}$; nebulizer, $0.85 \mathrm{~L} \mathrm{~min}^{-1}$, sample, $0.85 \mathrm{~L} \mathrm{~min}^{-1}$, pump rate,
$30 \mathrm{rpm}$; nebulizer, crossbow; emission line, $267.60 \mathrm{~nm}$. For the ICP-OES analysis, the sample was digested in an open system using a mixture of acids $\left(\mathrm{HNO}_{3}, \mathrm{HCl}\right.$ and $\mathrm{HF}$; 0.5:1.5:1, respectively) under heating in a Tecnal digester block, model TE-015-1 (Sao Paulo, Brazil).

\section{Other characterizations}

Transmission electron microscopy (TEM) was performed on an FEI Tecnai G2 Spirit TWIN electron microscope (Hillsboro, USA) at an accelerating voltage of $120 \mathrm{kV}$, and the samples were prepared with the addition of a drop of the gold colloidal solution on a copper grid coated with a porous carbon film. UV-Vis diffuse reflectance spectroscopy (DRS) was performed using a 2600 spectrometer (Shimadzu, Kyoto, Japan) with a solid integrated sphere. The spectra were recorded with a spectral resolution of $8 \mathrm{~cm}^{-1}$, using the diffuse reflectance and absorption mode. The range analyzed was 400-1000 nm and the samples were placed on a support for solids and analyzed in triplicate.

\section{Results and Discussion}

To quantify the accessible gold content after the different sample treatments for AuNP/SiO ${ }_{2}$ and AuNP@ $\mathrm{SiO}_{2}$, three calibration curves were prepared, and the analytical parameters related to slope, intercept and the linear correlation coefficient were obtained.

The calibration curves were subjected to analysis of variance (ANOVA, one-way) to evaluate the sensitivity and the analytical blank in the different systems (S1, S2, and S3). It was observed that there was no significant difference between them at the $95 \%$ confidence level $\left(F_{\text {cal }}=0.008<F_{\text {critical }}=3.5545\right)$. Thus, the $2 \mathrm{~mol} \mathrm{~L}^{-1} \mathrm{HNO}_{3}$ solution curve was used for the gold quantification in subsequent experiments.

The accuracy of the proposed methods was evaluated by comparing the gold contents in a sample determined by FAAS and by ICP-OES. Using S2, the gold content obtained was $1.71 \pm 0.07 \%(\mathrm{~m} / \mathrm{m})$, while the result obtained employing ICP-OES was $1.82 \pm 0.10 \%(\mathrm{~m} / \mathrm{m})$. On applying the Student's $t$-test, it was observed that there is no significant difference between the two methods at the 95\% confidence level.

After determining the accuracy of the method, it was applied to samples of silica-supported gold nanoparticles $\left(\mathrm{AuNP} / \mathrm{SiO}_{2}\right)$ and the analogous core-shell system (AuNP@ $\mathrm{SiO}_{2}$ ). Table 2 shows the Au concentration for each of the samples, exploring the preparation strategies evaluated. It can be observed that $\mathrm{AuNP} / \mathrm{SiO}_{2}$ presented a 
Table 2. Gold content determined in nanoparticles by flame atomic absorption spectrometry applying different sample preparation strategies

\begin{tabular}{|c|c|c|c|c|c|c|}
\hline \multirow{3}{*}{ Sample } & \multicolumn{6}{|c|}{$\mathrm{Au} /(\%, \mathrm{~m} / \mathrm{m})$} \\
\hline & \multicolumn{3}{|c|}{$\mathrm{AuNP} / \mathrm{SiO}_{2}$} & \multicolumn{3}{|c|}{$\mathrm{AuNP} @ \mathrm{SiO}_{2}$} \\
\hline & $\mathrm{S} 1( \pm 0.02)$ & $\mathrm{S} 2( \pm 0.03)$ & $\mathrm{S} 3( \pm 0.07)$ & $\mathrm{S} 1( \pm 0.03)$ & $\mathrm{S} 2( \pm 0.04)$ & $\mathrm{S} 3( \pm 0.06)$ \\
\hline A1 & $<$ LOD & 1.56 & 1.51 & $<$ LOD & $<$ LOD & 2.65 \\
\hline A2 & $<$ LOD & 1.56 & 1.43 & $<$ LOD & $<$ LOD & 2.74 \\
\hline A3 & $<\mathrm{LOD}$ & 1.62 & 1.57 & $<$ LOD & $<$ LOD & 2.75 \\
\hline
\end{tabular}

Sample preparation strategies: $\mathrm{S} 1=\mathrm{HNO}_{3} 2 \mathrm{~mol} \mathrm{~L}{ }^{-1}+30$ min stirring at $600 \mathrm{rpm} ; \mathrm{S} 2=\mathrm{HNO}_{3}+\mathrm{HCl}+$ microwave; and $\mathrm{S} 3=\mathrm{HNO}+\mathrm{HCl}+\mathrm{HF}+$ microwave. The limit of detection (LOD, $3 \sigma$ ) was calculated as $0.10 \mathrm{mg} \mathrm{L}^{-1}$.

lower average gold content $(1.5 \% \mathrm{~m} / \mathrm{m})$ when compared to AuNP@ $\mathrm{SiO}_{2}(2.7 \% \mathrm{~m} / \mathrm{m})$.

On applying $\mathrm{S} 1\left(\mathrm{HNO}_{3}\right)$ to both nanostructured materials $\left(\mathrm{AuNP} / \mathrm{SiO}_{2}\right.$ and $\left.\mathrm{AuNP} @ \mathrm{SiO}_{2}\right)$ it was not possible to quantify the ionic gold content $\left(\mathrm{Au}^{3+}\right)$, which indicates that most of the gold present is in the reduced form $\left(\mathrm{Au}^{0}\right)$.

The AuNP/SiO $/ \mathrm{S}_{2}$ and AuNP@ $\mathrm{SiO}_{2}$ samples after the S2 treatment were dried and characterized by solid-state UV-Vis spectroscopy and the spectra obtained for the systems evaluated are shown in Figure 1. It can be noted that for the AuNP@ $\mathrm{SiO}_{2}$ samples the intensity and profile of the surface plasmon absorption band at around $525 \mathrm{~nm}$ (before and after digestion) is similar and characteristic of gold ball-shaped nanoparticles. ${ }^{11,21}$ For the AuNP/SiO${ }_{2}$ sample after the $\mathrm{S} 2$ treatment, the plasmon absorption band is absent, indicating that all gold nanoparticles had been removed from the sample surface. Thus, the UV-Vis spectroscopy results corroborate with the expected data obtained for the sample preparation procedures used.

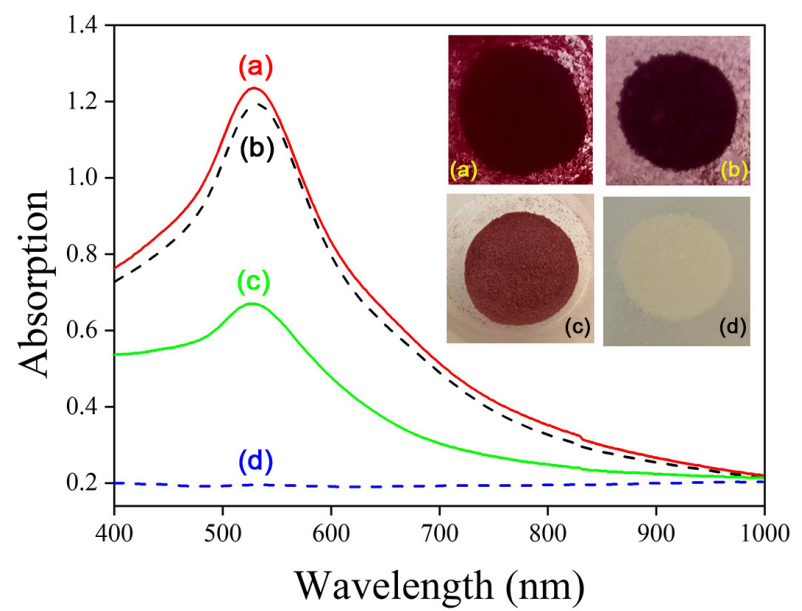

Figure 1. Absorption spectra and corresponding images were obtained by solid-state UV-Vis spectroscopy, for AuNP@ $\mathrm{SiO}_{2}$ : (a) before and (b) after strategy S2 and $\mathrm{AuNP}_{\mathrm{SiO}}$ : (c) before and (d) after strategy S2. The $\mathrm{S} 2=\mathrm{HNO}_{3}+\mathrm{HCl}$, using MW. The pictures insert to represent the nanoparticles synthesized.

After digestion of the AuNP@ $\mathrm{SiO}_{2}$ samples (Figure 1a), it was not possible to detect the gold content using strategy $\mathrm{S} 2\left(\mathrm{HNO}_{3}+\mathrm{HCl}+\mathrm{MW}\right)$, and no visual changes were observed in the aspect of the remaining material (Figure 1b). This result indicates the presence of gold nanoparticles inside the nanomaterial (metal on core) is consistent with a core-shell structure, ${ }^{21,22}$ i.e., the gold nanoparticle is covered by a nonporous silica layer, protecting the AuNP core ${ }^{23}$ during the $\mathrm{S} 2$ treatment. In fact, for S2, on comparing the images of the AuNP@ $\mathrm{SiO}_{2}$ samples before and after digestion (Figures $1 \mathrm{a}$ and $1 \mathrm{~b}$, respectively), it can be observed that the proposed digestion conditions failed to extract the gold nanoparticles present in the silica.

On the other hand, on applying S2, it is possible to detect and quantify the gold content in the $\mathrm{AuNP} / \mathrm{SiO}_{2}$ sample, since the AuNPs are supported on the silica particles. After microwave-assisted digestion, a white solid powder was recuperated by filtration (Figure 1d), in contrast to the dark red color of the sample before the S2 treatment (Figure 1c).

Both the AuNP/SiO 2 and AuNP@ $\mathrm{SiO}_{2}$ samples were entirely solubilized after the $\mathrm{S} 3$ digestion $\left(\mathrm{HNO}_{3}+\mathrm{HCl}+\mathrm{HF}+\mathrm{MW}\right)$, leaving the gold available for quantification as $\mathrm{Au}^{3+}$. For the $\mathrm{AuNP} / \mathrm{SiO}_{2}$ sample, in which the metal is found only on the surface of the silica, no significant difference in the Au contents was observed on applying the $\mathrm{S} 2$ and $\mathrm{S} 3$ procedures (Table 1), with $95 \%$ confidence applying the Student's paired $t$-test. However, for the AuNP@ $\mathrm{SiO}_{2}$ sample, the gold was only quantified after treatment $\mathrm{S} 3$, confirming the protection effect of the silica. Therefore, employing the three different sample preparation strategies in a wet system it was possible not only to quantify the amount of gold in the material but also to characterize the structure of the nanomaterial. Finally, Scheme 1 shows a compilation of all the strategies employed in this work.

When the $\mathrm{S} 1$ (diluted $\mathrm{HNO}_{3}$ solution) procedure was applied to the samples $\left(\mathrm{AuNP} / \mathrm{SiO}_{2}\right.$ and $\left.\mathrm{AuNP} @ \mathrm{SiO}_{2}\right)$ the concentration of $\mathrm{Au}^{3+}$ was lower than the limit of detection (LOD), indicating that practically all of the gold content was in its reduced form $\mathrm{Au}^{0}$ as nanoparticles (Table 1). In 
S1

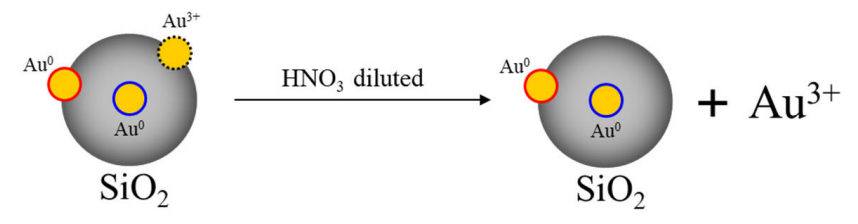

S2

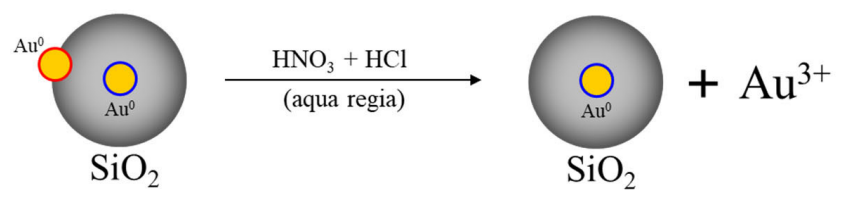

S3

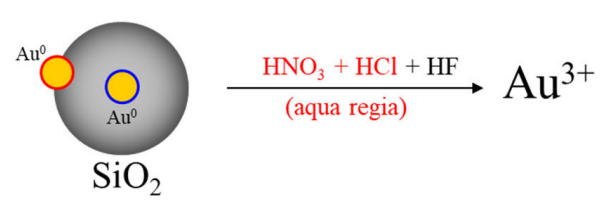

$=$ ionic metal $\left(\mathrm{Au}^{3+}\right)$

$\mathrm{O}=$ metal on shell $\left(\mathrm{Au}^{0}\right)$

$=$ metal on core $\left(\mathrm{Au}^{0}\right)$

Scheme 1. Summary of strategies and information obtained for the different systems evaluated.

the $\mathrm{S} 2$ procedure (aqua regia), all of the gold content was converted to $\mathrm{Au}^{3+}$ as the tetrachloroaurate ion $\left(\mathrm{AuCl}_{4}^{-}\right)$, according to equation 1 . With the application of the $\mathrm{S} 3$ procedure, the silica was dissolved due to the presence of $\mathrm{HF}$, according to equation 2 , allowing the reaction of aqua regia with the metal core.

$$
\begin{aligned}
& 2 \mathrm{Au}_{(\mathrm{s})}+11 \mathrm{HCl}_{(\mathrm{aq})}+3 \mathrm{HNO}_{3(\mathrm{aq})} \rightarrow 2 \mathrm{HAuCl}_{4}^{-}(\mathrm{aq}) \\
& 3 \mathrm{NOCl}_{(\mathrm{aq})}+6 \mathrm{H}_{2} \mathrm{O}_{(\mathrm{l})} \\
& \mathrm{SiO}_{2(\mathrm{~s})}+6 \mathrm{HF}_{(\mathrm{aq})} \rightarrow \mathrm{H}_{2} \mathrm{SiF}_{6(\mathrm{aq})}+2 \mathrm{H}_{2} \mathrm{O}_{(\mathrm{l})}
\end{aligned}
$$
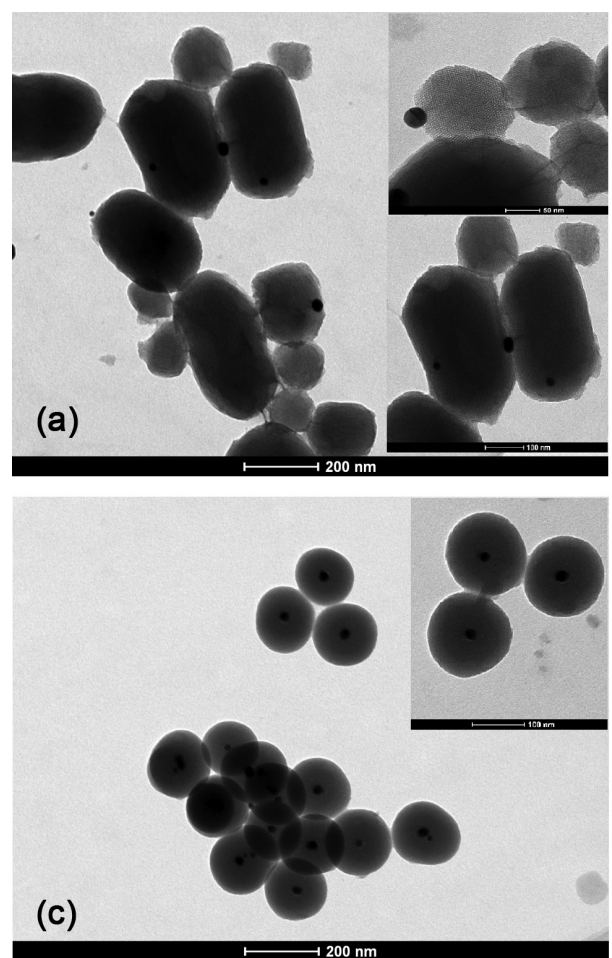

Figure 2. TEM micrographs for $\mathrm{AuNP} / \mathrm{SiO}_{2}$ before (a) and after (b) treatment with $\mathrm{S} 2$, and $\mathrm{AuNP} @ \mathrm{SiO}_{2}$ before (c) and after (d) treatment with S2.
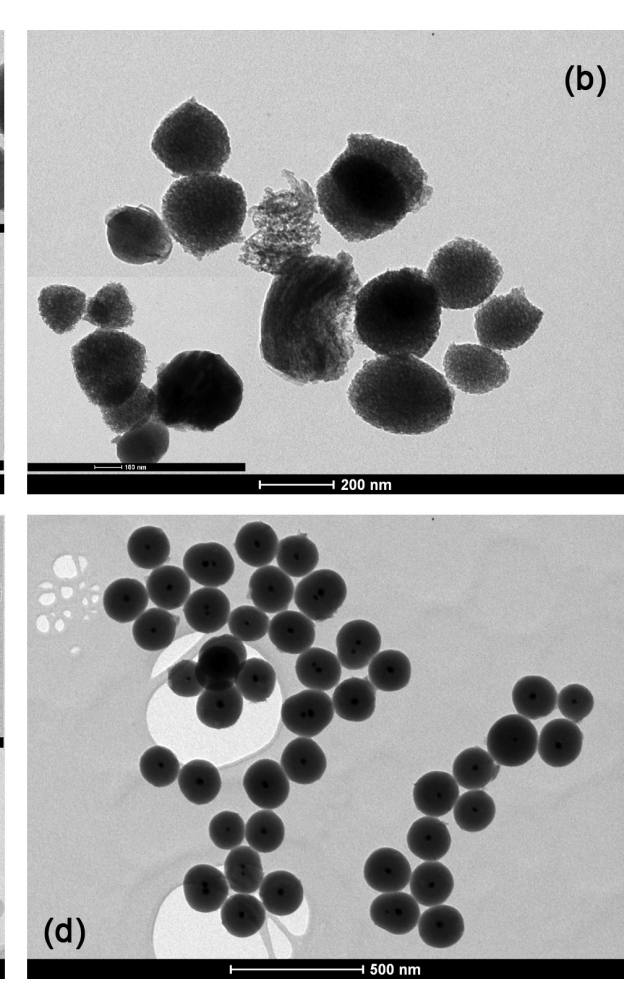

Additionally, the samples were characterized by transmission electron microscopy (TEM) before and after the treatment procedure S2 (Figure 2). After the treatment, the micrographs for $\mathrm{AuNP} / \mathrm{SiO}_{2}$ revealed that the gold nanoparticles had been removed. It was also observed that the treatment promoted modification of the morphology of the silica matrix, since there was an increase in surface roughness and the potential formation of larger pores (Figure 2b). On the other hand, on comparing Figures 2c and $2 \mathrm{~d}$, it can be seen that the silica-encapsulated gold

Figure 2. TEM micrographs for AuNP/SiO 2 before (a) and after (b) treatment with S2, and AuNP@SiO2 before (c) and after (d) treatment with S2. 
nanoparticles (AuNP@ $\mathrm{SiO}_{2}$ ) did not undergo structural changes after the sample treatment process, and the AuNPs are evenly distributed within the silica nanoparticles. This can be explained mainly by the fact that the silica shell in AuNP@ $\mathrm{SiO}_{2}{ }^{16,17}$ is amorphous, with a low surface area, in contrast with the mesoporous silica used as a support in $\mathrm{AuNP} / \mathrm{SiO}_{2} \cdot{ }^{18,19}$

\section{Conclusions}

Different sample preparation strategies for the quantification and characterization of samples with the same composition but different structural arrangements, in this case AuNP/SiO $\mathrm{Si}_{2}$ and AuNP@ $\mathrm{SiO}_{2}$, were investigated. The results indicate that with the application of the $\mathrm{S} 1$ procedure $\left(2 \mathrm{~mol} \mathrm{~L}^{-1} \mathrm{HNO}_{3}+30 \mathrm{~min}\right.$ stirring at $\left.600 \mathrm{rpm}\right)$ all of the gold added to obtain the nanoparticles was reduced $\left(\mathrm{Au}^{3+} \rightarrow \mathrm{Au}^{0}\right)$. The combination of $\mathrm{S} 2\left(\mathrm{HNO}_{3}+\mathrm{HCl}+\mathrm{MW}\right)$ and $\mathrm{S} 3\left(\mathrm{HNO}_{3}+\mathrm{HCl}+\mathrm{HF}+\mathrm{MW}\right)$ allows the presence of AuNPs on or in the silica matrix to be distinguish, i.e., the presence of supported or core-shell gold-silica nanoparticles was determined. The results are in agreement with the TEM micrographs and spectra obtained using solid-state UV-Vis spectroscopy. Moreover, based on the difference between strategies $\mathrm{S} 2$ and $\mathrm{S} 3$, it is possible to determine the gold content in or on the silica matrix present in the two types of material (silica-supported AuNPs and core-shell gold-silica NPs).

\section{Acknowledgments}

Financial support from the Brazilian research funding agencies Research and Projects Financing (FINEP), National Council of Technological and Scientific Development (CNPq), Alagoas Research Support Foundation (FAPEAL), and INCT-Catalysis are gratefully acknowledged. This study was financed in part by the Coordenação de Aperfeiçoamento de Pessoal de Nível Superior - Brasil (CAPES) - Finance Code 001. MRM and JCCS thank CNPq for the research fellowships. CJG, MJO, and ESF thank CAPES for a fellowship. Authors thank LabMET/Ufal for the transmission electron micrographs.

\section{Author Contributions}

Cristian J. Giertyas was responsible for data curation, formal analysis, investigation, methodology, writing original draft, review and editing; Victor E. S. Silva for data curation, formal analysis, investigation, and methodology; Maria J. de Oliveira for data curation, formal analysis, investigation, methodology, and writing original draft; Emerson S. Freire for data curation, formal analysis, and methodology; Josué
C. C. Santos for investigation, methodology, and writing original draft, and writing review and editing; Rusiene M. de Almeida for formal analysis, methodology, supervision, and writing original draft; Mario R. Meneghetti for conceptualization, data curation, funding acquisition, investigation, methodology, project administration, resources, supervision, writing original draft, review and editing; Janaína H. Bortoluzzi for conceptualization, data curation, formal analysis, funding acquisition, investigation, methodology, project administration, resources, supervision, writing original draft, review and editing.

\section{References}

1. Li, Y.; Somorjai, G. A.; Nano Lett. 2010, 10, 2289.

2. Harding, C.; Habibpour, V.; Kunz, S.; Farnbacher, A. N.-S.; Heiz, U.; Yoon, B.; Landman, U.; J. Am. Chem. Soc. 2009, 131, 538.

3. Yeh, Y.-C.; Creran, B.; Rotello, V. M.; Nanoscale 2012, 4, 1871.

4. Gualteros, J. A. D.; Garcia, M. A. S.; da Silva, A. G. M.; Rodrigues, T. S.; Cândido, E. G.; e Silva, F. A.; Fonseca, F. C.; Quiroz, J.; de Oliveira, D. C.; de Torresi, S. I. C.; de Moura, C. V. R.; Camargo, P. H. C.; de Moura, E. M.; J. Mater. Sci. 2019, $54,238$.

5. Alshammari, A. S.; Catalysts 2019, 9, 402.

6. Cavaliere-Jaricot, S.; Darbandi, M.; Nann, T.; Chem. Commun. 2007, 2031.

7. Lekeufack, D. D.; Brioude, A.; Mouti, A.; Alauzun, J. G.; Stadelmann, P.; Coleman, A. W.; Miele, P.; Chem. Commun. 2010, 46, 4544.

8. Gutiérrez, L.-F.; Hamoudi, S.; Belkacemi, K.; Catalysts 2011, $1,97$.

9. Liberman, A.; Mendez, N.; Trogler, W. C.; Kummel, A. C.; Surf. Sci. Rep. 2014, 69, 132.

10. Li, Y.; Somorjai, G. A.; Nano Lett. 2010, 10, 2289.

11. Villa, A.; Dimitratos, N.; Chan-Thaw, C. E.; Hammond, C.; Veith, G. M.; Wang, D.; Manzoli, M.; Prati, L.; Hutchings, G. J.; Chem. Soc. Rev. 2016, 45, 4953.

12. Allen, L. J.; D’Alfonso, A. J.; Freitag, B.; Klenov, D. O.; MRS Bull. 2012, 37, 47.

13. Tiruvalam, R. C.; Pritchard, J. C.; Dimitratos, N.; Lopez-Sanchez, J. A.; Edwards, J. K.; Carley, A. F.; Hutchings, G. J.; Kiely, C. J.; Faraday Discuss. 2011, 152, 63.

14. Shibata, N.; Goto, A.; Matsunaga, K.; Mizoguchi, T.; Findlay, S. D.; Yamamoto, T.; Ikuhara, Y.; Phys. Rev. Lett. 2009, 102, 136105.

15. López-Haro, M.; Cíes, J. M.; Trasobares, S.; Pérez-Omil, J. A.; Delgado, J. J.; Bernal, S.; Bayle-Guillemaud, P.; Stéphan, O.; Yoshida, K.; Boyes, E. D.; Gai, P. L.; Calvino, J. J.; ACS Nano 2012, 6, 6812 .

16. Huh, S.; Wiench, J. W.; Yoo, J.-C.; Pruski, M.; Lin, V. S.-Y.; Chem. Mater. 2003, 15, 4247. 
17. Trewyn, B. G.; Slowing, I. I.; Giri, S.; Chen, H.-T.; Lin, V. S.-Y.; Acc. Chem. Res. 2007, 40, 846.

18. Arnal, P. M.; Comotti, M.; Schüth, F.; Angew. Chem., Int. Ed. Engl. 2006, 45, 8224.

19. Fang, X.; Chen, C.; Liu, Z.; Liu, P.; Zheng, N.; Nanoscale 2011, 3,1632 .

20. Niemelä, M.; Pitkäaho, S.; Ojala, S.; Keiski, R. L.; Perämäki, P.; Microchem. J. 2012, 101, 75.

21. Törngren, B.; Akitsu, K.; Ylinen, A.; Sandén, S.; Jiang, H.; Ruokolainen, J.; Komatsu, M.; Hamamura, T.; Nakazaki, J.;
Kubo, T.; Segawa, H.; Österbacka, R.; Smått, J.-H.; J. Colloid Interface Sci. 2014, 427, 54.

22. Kalele, S.; Gosavi, S. W.; Urban, J.; Kulkarni, S. K.; Curr. Sci. 2006, 91, 1038.

23. Tessarolli, B. O.; da Silva, P. V.; Gallardo, E. C.; Magdalena, A. G.; Matéria (Rio de Janeiro) 2019, 24.

Submitted: August 24, 2021 Published online: November 22, 2021 